Article

\title{
Implementation of Modeling Tools for Teaching Biorefinery (Focused on Bioethanol Production) in Biochemical Engineering Courses: Dynamic Modeling of Batch, Semi-Batch, and Continuous Well-Stirred Bioreactors
}

\author{
M. Ángeles Martín-Lara ${ }^{1, *(1)}$ and Alicia Ronda ${ }^{2}$ \\ 1 Chemical Engineering Department, Faculty of Sciences, University of Granada, 18071 Granada, Spain \\ 2 Chemical and Environmental Department, Higher Technical School of Engineering, University of Seville, \\ 41092 Seville, Spain; aronda@us.es \\ * Correspondence: marianml@ugr.es; Tel.: +34-958-240-445
}

Received: 30 September 2020; Accepted: 2 November 2020; Published: 4 November 2020

\begin{abstract}
Due to the ever-growing pressure on our planet's natural resources to supply energy, the production of bioethanol by fermentation of lignocellulosic biomass is increasingly important in courses related to engineering and energy. Moreover, recent changes in the teaching-learning paradigm make necessary the introduction of novel teaching tools where students are the protagonist of their education. In this context, the purpose of this study is to compare the results obtained after traditional lessons with those obtained after the implementation of various computer activities based on modeling and simulation of bioreactors to teach biorefinery concepts focused on bioethanol production. Berkeley Madonna was chosen as the digital simulation software package because it is user-friendly, fast, and easy to program. This software allowed students to gain experience writing models that let optimize fermentations in well-stirred bioreactors and others bioprocess of industrial interest. The students (those who participated in the modeling-simulation classes and those who participated in traditional ones) completed a questionnaire and a cognitive test at the end of the course. Students that participated in modeling-simulation classes got a better score than students that participated in traditional classes. Therefore, the study showed the improvement in the understanding of the biorefinery concepts and the students improved their grades. Finally, students' perception about the proposed modeling-simulation learning was also analyzed and they rated the efficiency of this new learning methodology as satisfactory. There are very few studies providing information about educational experiences regarding the development of skills for the formulation, interpretation, simplification, and use of mathematical models based on mass balances and simple microbial kinetics in biochemical engineering courses. The experience described in this work can be used by professors to plan and conduct courses based on the modeling of biochemical engineering problems.
\end{abstract}

Keywords: biofuels; bioprocesses; challenge-based learning; computer-based learning; energy engineering; higher education

\section{Introduction}

With an ever-growing population, the pressure on our planet's natural resources to supply materials, chemicals, and energy continues to rise. A biorefinery produces biofuels and/or biochemicals and/or bioenergy from biomass using different conversion methods, mainly thermochemical and/or biochemical conversion procedures [1]. Inside biofuels, the bioethanol represents good energy 
properties, contributing to fossil primary energy savings (in automotive industry applications, it can replace gasoline for spark-ignition engines) [2,3]. Some studies indicate that Europe bioethanol production for fuel purposes has increased from $9.2 \%$ in 1998 to over $70 \%$ in 2009 [4].

Therefore, in the last years, the production of bioethanol by fermentation of lignocellulosic biomass is widely explained in courses related to engineering and energy. Moreover, due to the incorporation of the University to European Higher Education Area (EHEA), numerous changes in the teaching-learning models have been made $[5,6]$ and the students must be the protagonist of their education, being the professor, the supervisor aiding their acquisition of skills $[7,8]$. The students take responsibility for their own learning, being active discoverers and constructors of their own knowledge, supporting any learning method that works [6,9]. Authors such as Venkatraman et al. [10] indicated that the world is experiencing the fourth industrial revolution and that education systems need to be redesigned in order to meet the new needs, due to the level of automation in the industry that has increased in the last decades. Science, Technology, Engineering, and Mathematics (STEM) students have to deal with complex models of real-life systems [11,12]. Thus, the incorporation of novelty tools during higher education lessons improves the degree, plans and encourages the work-based learning, besides bringing students closer to their future job. These kinds of activities promote the autonomous work of students and they can reinforce their knowledge, modifying or increasing the level of the proposed activities. In the same way, the professor can contrast the evolution of students analyzing the obtained results [8]. In this work, the aim of the authors is to analyze the results obtained after the implementation of modeling tools for teaching biorefinery in biochemical engineering courses.

In this context, when planning biochemical engineering courses, new methodologies have to be included in the course programs to close the gap between developers' vision and the real-life application in STEM students [13]. Educational institutions usually rely on laboratory practices to build successful students. However, computer skills involving various software are not taught in sufficient detail, and in most cases, students will face more work with practical software tools than with experimentation in the laboratory, as Venkatraman et al. cited in their study [10]. Moreover, one of the most common complaints from students is the low amount of practical activities with these kind of tools. Hence, the STEM degrees must strive to provide more practical learning [11,14]. In this sense, the proposed methodology aims to fill this gap in computer skills in biochemical engineering courses.

Mathematical modeling has always been a fundamental methodological procedure to solve problems in engineering, allowing the representation of the problem in an appropriate way for its treatment with specific software. In biochemical engineering, the modeling is key to understand the real fermentation process and to know the mechanisms involved during the production of bioethanol as an energy source. Moreover, the modeling is necessary in the design of industrial-sized equipment; in the control and optimization of the processes; and in the running of simulations as an alternative to expensive experiments in development laboratories $[15,16]$. Therefore, the insertion of modeling tools in STEM courses can be a useful teaching tool for students. The objective of this innovation was to give the students insight and skills in the modeling tools based on mass balances and simple microbial kinetics for the study of batch, semi-batch, and continuous well-stirred bioreactors for the production of bioethanol in fermentation-based biorefineries.

Although, usually, process engineers and scientists use simulation models to investigate biorefinery operations, a recent literature review recognized only a few studies that compared simulations in biorefinery teaching with the traditional classroom teaching [5,17-21]. For example, Ruiz-Ramos et al. [17] reported the use of ASPEN Plus ${ }^{\circledR}$ to design and assess a biorefinery from olive-derived biomass. The survey also suggested that students found this learning approach very useful. Bonde et al. [18] developed and tested a gamified biotech laboratory simulation platform. Potratz [19] demonstrated the value of simulations to enhance students' knowledge of enzyme kinetics dynamic in an upper-division biochemistry course. Lay and Swan [20] evaluated FermOpt as a tool for teaching fermentation and optimization principles. Authors found FermOpt a relaxed technique to 
engage student's attention and interest. In addition, although it was not exactly a modeling-simulation practice, Serrano-Aroca [21] encouraged students with exercises in a virtual bioreactor laboratory.

There are several challenges in the application of process simulation software to biorefinery teaching [22]. There are two basic approaches to perform simulations: (1) writing adequate mathematical models with software-oriented programming or (2) using block-oriented programming capable of mathematically modeling the performance of individual unit operations [23]. The first approach deals with the building of code-based algorithms that use specific syntax rules depending on the programming language used. Berkeley Madonna falls in this group of approach as a general-purpose differential equations solver that provides an ideal environment in which adequate mathematical models to perform simulations of bioethanol production by fermentation can be written. In addition, Berkeley Madonna software offers a free version that is only slightly restricted in functionality: the code and the setup (screen layout) cannot be saved [24].

Given the context of this study, the main goal of this work is to use the Berkeley Madonna software as an innovative teaching methodology to facilitate the learning of biorefineries processes (focused on bioethanol production) to undergraduate students of biochemical engineering courses. Several examples of obtaining the bioethanol by fermentation of lignocellulosic biomass in well-stirred bioreactors to model in Berkeley Madonna are presented to enhance the motivation, the participation, and grades of the students.

\section{Methodology}

\subsection{Framework for Applying the Innovative Methodology}

This research was conducted as part of a study of the incorporation of novelty tools during the higher education lessons. The innovation was conducted during 2 academic years in a course named "Biochemical Engineering Principles" which is lectured in the second course of the Biotechnology degree at the University of Granada (Spain). The modules in which the innovation was applied provide the fundamental basis of bioethanol bioengineering based on the biorefinery concept. Figure 1 shows the course framework.

The methodology promoted the use of the software Berkeley Madonna to solve and simulate the bioethanol production by the mathematical modeling of the fermentation process and the mechanisms involved in it. The total number of students who completed the course was 101 (55 during 2016-2017 course and 46 during 2017-2018 course). The modeling-simulation experience was carried out with 46 and 38 students in each academic year, respectively, while the rest of students received the classes following a traditional teaching method. It is important to highlight that both groups had similar content: the dynamic modeling of batch, semi-batch, and continuous well-stirred bioreactors focused on fermentation-based biorefineries and the same background, time restrictions, and teacher.

The aim of this innovation was to give the students insight and skills in the formulation, interpretation, simplification, and use of mathematical models inside the framework of the biochemical engineering course. They allow students a better understanding of batch, semi-batch, and continuous well-stirred bioreactors for the production of bioethanol in fermentation-based biorefineries, based on mass balances and simple microbial kinetics for the study. 


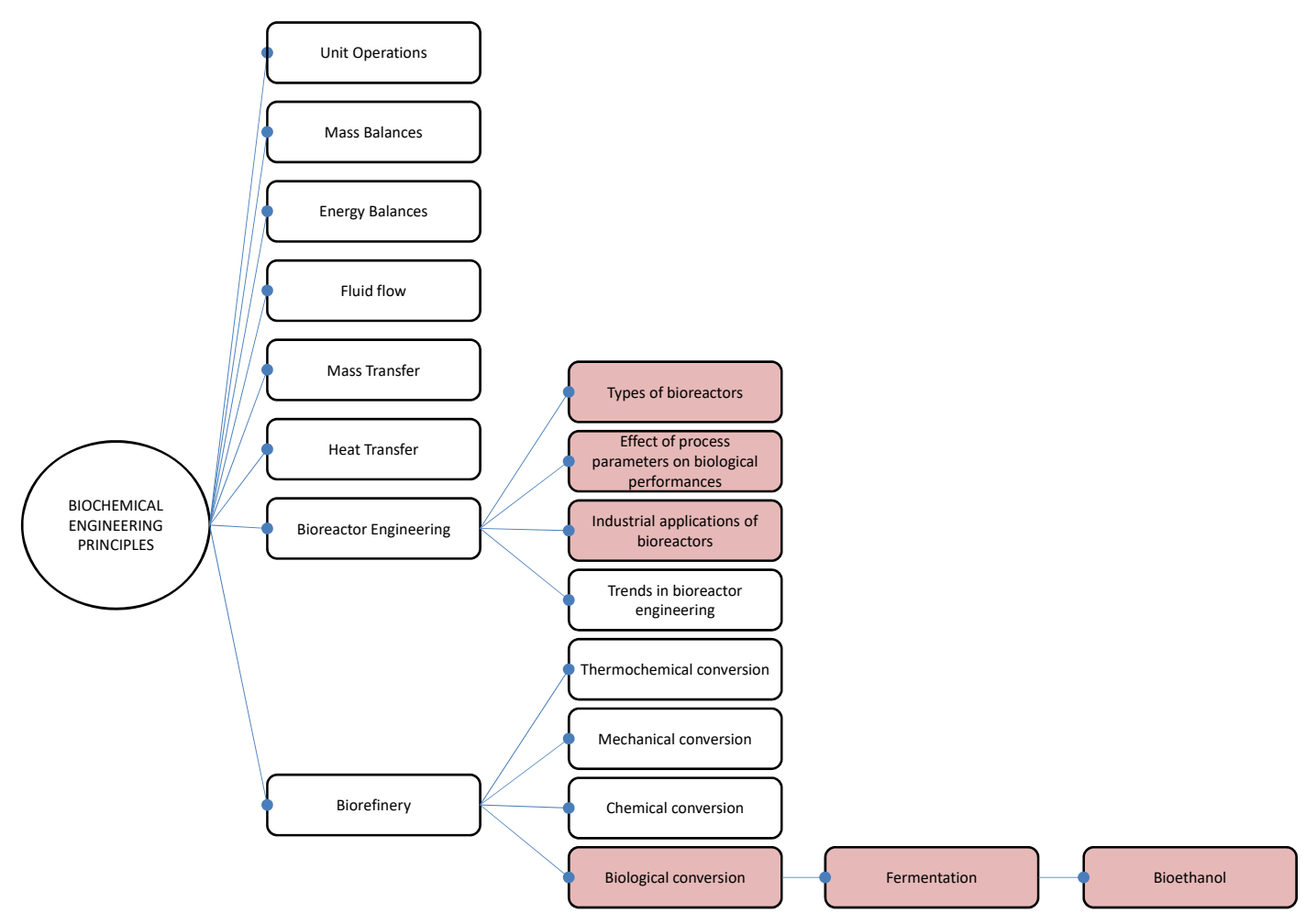

Figure 1. Course framework (themes linked to investigation are marked in red).

\subsection{Organization of the Modeling-Simulation Classes}

The modeling-simulation classes (a total of four sessions) were divided in five different parts each one. In the first session, a total of $4 \mathrm{~h}$, was used for parts I, II, III, and IV and the second, third, and four sessions, a total of $12 \mathrm{~h}$, were used to complete the most interesting part of this work, the part $\mathrm{V}$.

- Part I: to provide the basic theory required to understand the different modes of operation of the well-stirred tank-type bioreactors. In this part, derivations of general mass balance equations of all types of tank-type bioreactors were presented.

- Part II: to provide the basic theory required to understand simple microbial kinetics. In this part, explanations of the main unstructured models for describing microbial kinetics were given. In addition, information about stoichiometry and the yield coefficient concept were provided.

- Part III: to provide concrete examples to students about a model equations formulation and to explain the methodology to establish the model equations.

- Part IV: to introduce the Berkeley Madonna to the students and to show how the software operates.

- Part V: to solve a series of exercises using Berkeley Madonna for each one of the proposed well-stirred bioreactor. Students could work together and discuss ideas for optimization, while the teacher was available to answer questions.

In the traditional learning scenario, the total time, $16 \mathrm{~h}$, was used to develop Part I, Part II, and Part III. In this case, $4 \mathrm{~h}$ were dedicated to each part using lectures and students were taught in a manner that is conducive to sitting and listening. Only in the development of part III, the students performed some work invidually to apply the content of the subject.

Table 1 reports a comparison between both teaching scenarios. 
Table 1. Comparison between the strategies of the modeling-simulation and traditional learning scenario.

\begin{tabular}{ccc}
\hline Elements & Modeling-Simulation Classes & Traditional Classes \\
\hline Part I & $2 \mathrm{~h}$. Lectures by the teacher & $4 \mathrm{~h}$. Lectures by the teacher \\
Part II & $1 \mathrm{~h}$. Lectures by the teacher & $4 \mathrm{~h}$. Lectures by the teacher \\
Part III & $1 \mathrm{~h}$. Lectures by the teacher & 4h. Lectures by the teacher and individual work completed by students \\
Part IV & 1 h. Lectures by the teacher & applying the content of the subject. \\
Part V & 11 h. Problem-solving teamwork & - \\
\hline
\end{tabular}

Figure 2 shows a graphical representation of the topics covered in this work including a closed-loop process of educational innovation. The aim is to evaluate the effect of the proposed methodology tools in STEM students through cognitive engagement, and due to previous studies, shows that students who are actively engaged with learning materials demonstrate greater learning gains that those who are passively engaged [9].

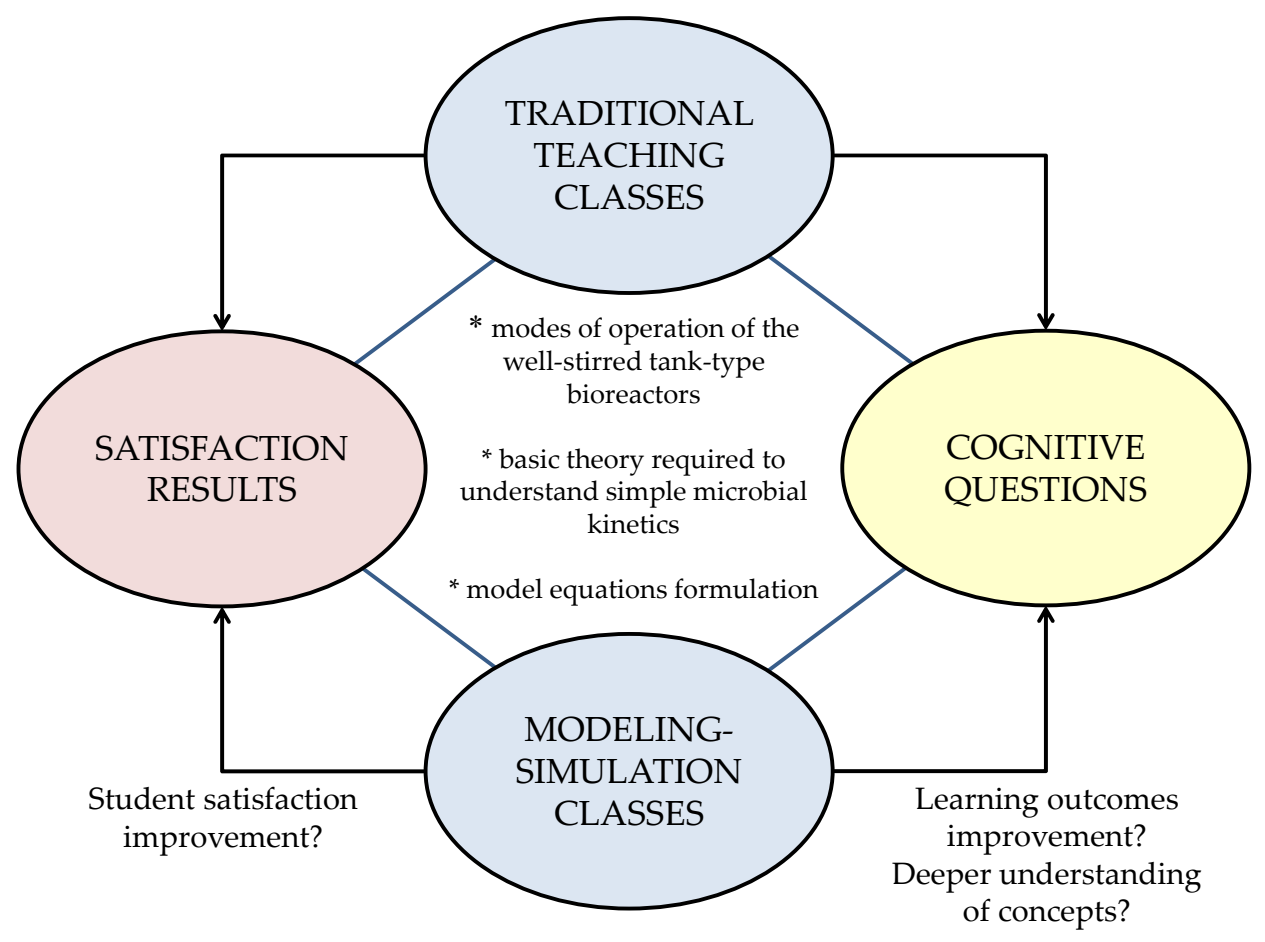

Figure 2. Graphical representation of the topics covered in this work.

\subsection{Modeling-Simulation Examples/Scenarios}

Different activities were proposed in each example or scenario. The complete examples are based on the book of Dunn et al. [25] and Martín-Lara and Ronda [26] about biological reaction engineering. In order to guide the students to solve different scenarios, guidelines with the methodology for the formulation of model equations were proposed. The suggested guidelines are the following:

1. Choose the balance region such that the variables are constant and change as little as possible within the system. Draw boundaries around the chosen balance region.

2. Identify the transport streams which flow across the system boundaries.

3. Write the general mass balance in word form.

4. Express each balance term in mathematical form with measurable variables.

5. Introduce other relationships and balances such that the number of equations equals the number of dependent variables.

6. For additional insight with complex problems, draw an information flow diagram. 
7. Simulate the practical case on Berkeley Madonna and discuss the simulation visualization.

From the materials and skills given to the students, they should formulate the model equations for each system and solve the proposed activities. The first activity of each practice is to formulate the model equations that characterize the system according to specifications provided by the teacher. The model equations for each proposed system have to be formulated according to Berkeley Madonna specifications. In order to increase the competences of students in terms of knowledge of the fermentation process, three different scenarios were proposed and different understanding activities were suggested for each system.

\subsubsection{Batch Fermentation}

The first strategy applied was batch fermentation. In these bioreactors, the production is not continuous and reaction conditions change with the time. In addition, some time for cleaning and filling is necessary. First, the bioreactor is organized for a charge of medium, and second, it is inoculated with cells and the cells are allowed to grow for a necessary time, such that the cells achieve the required cell density or optimum product concentrations [25].

In this scenario, students must complete several exercises. The first one was to formulate the model equations that characterize the system according to specifications provided by the teacher. In the second, students must run the model, giving concrete values to the parameters and analyzing the influence of the variation of the saturation constant, the maximum growth rate, and the yield biomass-substrate in the concentration of biomass, substrate, and product. Then, they must analyze the production of bioethanol by the microorganism because of fermentation under different conditions. Finally, from some provided experimental data, students must determine several parameters of the proposed system.

\subsubsection{Fed-Batch Fermentation}

In semi-continuous or fed batch operation, additional supply of nutrients is fed into the bioreactor. However, no material is removed from it. This example is comprised of five different exercises, like those proposed in batch fermentation, involving changes in the operational model. The first exercise was to formulate the model equations that characterize the system according to specifications provided by the teacher. The second exercise was to show the biomass, substrate, and product concentration by running the model with proposed parameters and to study the effect of volumetric flow onto these concentrations. In the third exercise, a new model had to been proposed considering that there is inhibition by substrate. The fourth exercise was to solve the model with proposed parameters and to study the effect of the inhibition constant onto the obtained amount of product. The fifth exercise was to compare the behavior of batch fermentation versus semi-batch fermentation. Finally, the sixth exercise consisted of the application of the model to a biological nitrogen removal problem.

This operation mode improves the yield versus the batch reactor, improving the control of nutrients concentration in the process. Although, it is not usually employed in the bioethanol production, it is important for students to know the differences between each possible operational scenario.

\subsubsection{Continuous Fermentation}

In the continuous operation mode, fresh medium is added continuously to the bioreactor, while at the same time, the exhausted medium (containing the products excreted by the cells) is removed. If the bioreactor is perfectly mixed, the concentrations of nutrients, cells, and other components throughout the entire bioreactor are uniform, and are identical to the concentration of the effluent stream [25]. It is the most widely used mode in the industrial processes, including bioethanol production.

Students must complete several different exercises (similar to other scenarios) and compare obtained results. The first exercise was to formulate the model equations that characterize the system, as in previous practices. The second one was to solve the model according to the proposed parameters 
by the teacher; moreover, students must determine some parameters and answer some understanding question about the model. The third exercise was to determine various parameters according to the proposed specifications by using the software tools. The fourth exercise was to model the behavior of both microorganism populations which interact and study the effect of the flow and the substrate concentration fed in the system. Finally, the fifth was to apply the model in a specific case and to study the behavior modifying various parameters.

As a case example, Figure 3 shows the outcomes of Berkeley Madonna for some different activities and scenarios $(\mathrm{a}-\mathrm{d})$. Students indicated that the outcomes of dynamic modeling simulations provided a clear and easily understanding of the process, allowing better learning of the bioethanol production.

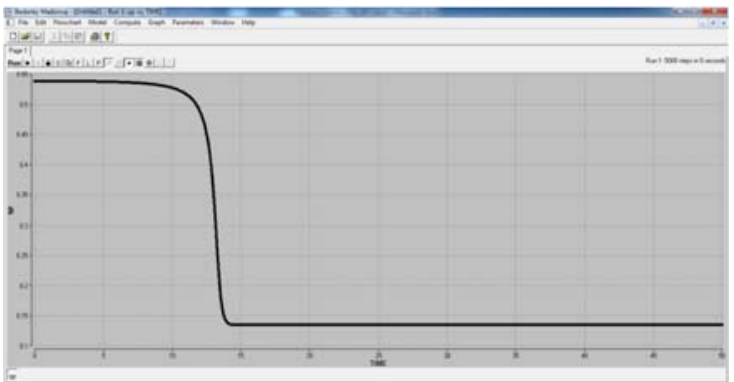

(a)

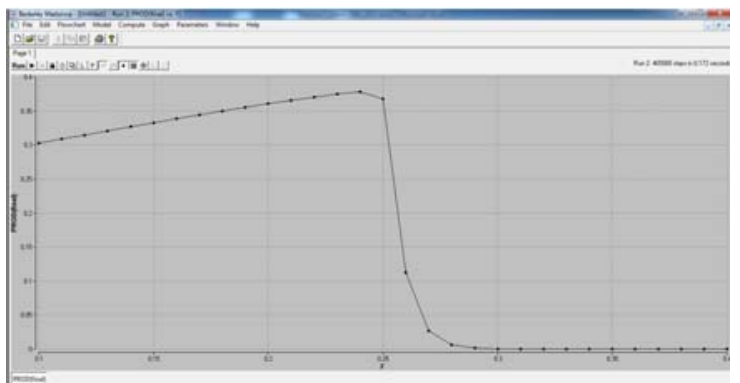

(c)

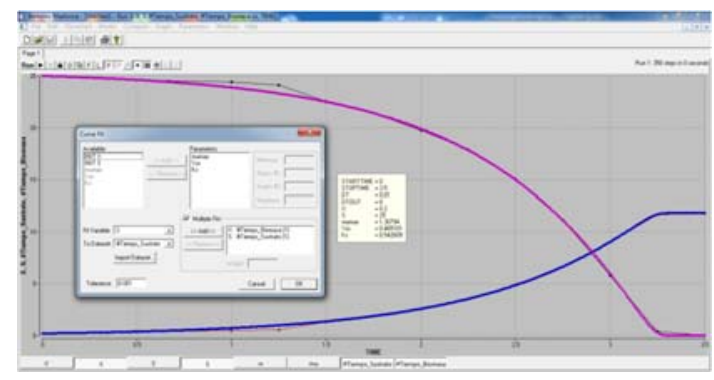

(b)

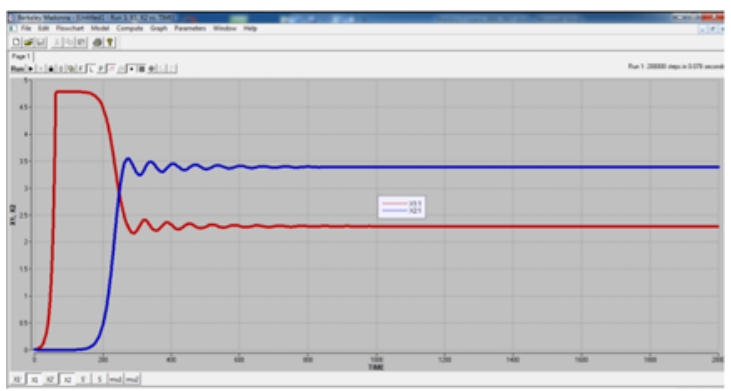

(d)

Figure 3. Berkeley Madonna simulation results of (a) activity four for the batch fermentation-specific velocity of ethanol production using Z. mobilis, (b) activity five for the batch fermentation-determination of the maximum specific growth rate $\left(\mu_{\max }\right)$, the substrate affinity constant $\left(K_{s}\right)$, the yield coefficient biomass-substrate $\left(\mathrm{Y}_{\mathrm{XS}}\right)$, considering a Monod growth to obtain a good fit of some experimental data, (c) activity two for the continuous fermentation-productivity in function of feed volumetric flow, and (d) activity three for the continuous fermentation-influence of the feed volumetric flow and the substrate concentration in the system (predatory-prey) behavior.

\subsection{Evaluation of Modeling-Simulation Classes}

The aim of this study was to give the needed guidelines to students to solve different systems of fermentations for the bioethanol production and others bioprocesses in well-stirred bioreactors as innovative educational activity, where the students must take responsibility for their own learning. In this way, applying this kind of methodology, it is intended to encourage students to be the protagonist of their teaching and the professor has a role of a supervisor during the acquisition of their skills [8,9].

Therefore, to evaluate the proposed model in the subject "Biochemical Engineering Principles" and the students' perspectives, they completed a questionnaire with 9 questions listed in Table 2, after performing modeling-simulation classes. The proposed questionnaire was answered anonymously in the classroom by students. The questionnaires were designed assuming they would be completed by all of the students participating in the course. When designing the questionnaires, a number scale was used for the answers, where they scored a total of 9 items on a scale of 1 (strongly disagree-absolutely no) to 5 (strongly agree-absolutely yes). The questionnaire was adapted from questionnaires provided 
in their works by Al-Moameri et al. [27], Larrañeta [28], and Zhu et al. [29]. Results of this questionnaire let to identify some key areas of the modeling-simulation classes that could be improved.

Table 2. Questions posed to students about their modeling-simulation (a) and traditional classes (b) experience.

\section{Motivation}

a. Do the modeling-simulation classes make the subject more interesting compared to the traditional learning? b. Do the classes make the subject interesting?

2. Content

a. Do you find that the topics covered in modeling-simulation classes were adequate and they stimulated your interest in the subject?

b. Do you find that the topics covered classes were adequate and they stimulated your interest in the subject? 3. Knowledge

a. After the modeling-simulation classes, do you know substantially more about training contents than before?

b. After the classes, do you know substantially more about training contents than before?

4. Helpfulness

a. Do modeling-simulation classes help you to learn complex topics that would be difficult to understand using traditional methods?

b. Do classes help you to learn complex topics that would be difficult to understand? 5. Skills

a. Do you think that the modeling-simulation classes were enriching your skills in biorefinery processes?

b. Do you think that the classes were enriching your skills in biorefinery processes?

6. Clearness

a. Do you think the modeling-simulation classes are clear in presenting the content?

b. Do you think the classes are clear in presenting the content?

7. Time

a. Do you think the modeling-simulation classes have an adequate duration for developing all proposed contents?

b. Do you think the classes have an adequate duration for developing all proposed contents?

8. Enjoyment

a. Do you think the modeling-simulation classes are more enjoying classes that traditional classes?

b. Do you think the classes are enjoying classes?

9. Recommendation

a. Do you recommend using the modeling-simulation classes as a learning method in future editions of course for teaching fermentation-based biorefinery concepts?

b. Do you recommend using the traditional learning method in future editions of course for teaching fermentation-based biorefinery concepts?

A cognitive test was also distributed to the students including four cognitive questions associated with theoretical explanations of fermentations in well-stirred bioreactors, in order to gauge the students' improvement in their level of knowledge of the fermentation process and involved mechanisms (see Table 3). Finally, a comparison between the scores of students that perform the computer activities and those of students that did not perform these activities was made.

Table 3. Cognitive questions associated with theoretical explanations of fermentations in well-stirred bioreactors.

1. Write the dynamics of the continuous well-stirred bioreactor for the production of bioethanol by the fermentation of lignocellulosic biomass.

2. Write a general set of differential equations describing the waste treatment facility that consists of a completely mixed biodigester and a settler. You can assume no growth and perfect separation occurs in the settler.

3. Determine stationary points and wash-out of a continuous well-stirred bioreactor.

4. Write a general set of differential equations describing the competition between two bacterial species in the batch well-stirred bioreactor.

\section{Results and Discussions}

Questionnaires were assessed after the classes to obtain the students' level of knowledge of the dynamic modeling of batch, semi-batch, and continuous well-stirred bioreactors used in the 
fermentation process in biorefineries, as well to determine their opinion regarding the type of classes used for the teaching.

Table 4 shows the results of the questionnaire expressed in percentage of each obtained score for each item, where column a shows results after performing modeling-simulation classes and column $b$ shows results after traditional classes. Moreover, the mean value for each question after each method is showed in Figure 4. A high level of motivation was measured for simulation classes, $88.1 \%$ of 84 students found them interesting (on a scale of 1 to 5 , with 4 and 5 representing "interesting"), confirming obtained results by other authors, as Serrano-Aroca [21], and reaching the proposed aims by the authors. Furthermore, $87.1 \%$ of students indicated that the topics covered in modeling-simulation classes were adequate and stimulated their interest in the subject. With respect to knowledge, $92.1 \%$ of students learned about fermentation by using the modeling-simulation classes. In this sense, results of this question were indicative of achieving the proposed methodology, due to that one of main aims of this study was to improve the training contents of the students in biochemical engineering courses. Therefore, authors consider that the implementation of modeling tools for teaching biorefinery is very useful for students. In addition, $88.1 \%$ of the students think that modeling-simulation classes helped them learn complex topics that would be difficult to understand using traditional methods. With regards to skills, $79.2 \%$ of students indicated that modeling-simulation classes enriched their skills as biotechnologists/biochemical engineers. With respect to clarity and duration, more than $80 \%$ of students found the modeling-simulation classes to be clear and with an appropriate duration. Finally, $86.1 \%$ of students think that the modeling-simulation classes were more enjoyable that traditional ones and $58.4 \%$ of them would recommend these classes as a learning method in future subjects. Although students thought that the modeling-simulation classes as a learning method helped the students to acquire competences, learn complex topics, and improve their skills in energy processes (questions 3, 4, and 5), from results of Figure 4 it is clear that the results were not as expected in question 9 , because the score about the recommendation of the students of the modeling-simulation classes as a learning method in future subjects was the lowest obtained (3.71). In this point, new studies are necessary to understand the low score of these questions. Authors think that perhaps the question is not well formulated and students considered not-teaching reasons (as problems in the computers or arrangement of the class) in their answers.

Table 4. Answers of students to the questionnaire after performing modeling-simulation classes (a) and traditional classes $(\mathbf{b})$. Values are expressed in percentage.

\begin{tabular}{cccccccccccc}
\hline & \multicolumn{2}{c}{$\mathbf{1}$} & \multicolumn{2}{c}{$\mathbf{2}$} & \multicolumn{2}{c}{$\mathbf{3}$} & \multicolumn{2}{c}{$\mathbf{4}$} & \multicolumn{5}{c}{$\mathbf{5}$} \\
\hline & $\mathbf{a}$ & $\mathbf{b}$ & $\mathbf{a}$ & $\mathbf{b}$ & $\mathbf{a}$ & $\mathbf{b}$ & $\mathbf{a}$ & $\mathbf{b}$ & $\mathbf{a}$ & $\mathbf{b}$ \\
\hline 1. Motivation & 3.96 & 11.76 & 1.98 & 11.76 & 5.94 & 35.29 & 39.60 & 23.53 & 48.51 & 17.65 \\
2. Content & 0.99 & 11.76 & 2.97 & 11.76 & 8.91 & 41.18 & 41.58 & 17.65 & 45.54 & 17.65 \\
3. Knowledge & 0.00 & 17.65 & 0.00 & 17.65 & 7.92 & 35.29 & 24.75 & 17.65 & 67.33 & 11.76 \\
4. Helpfulness & 2.97 & 23.53 & 1.98 & 17.65 & 6.93 & 35.29 & 31.68 & 11.76 & 56.44 & 11.76 \\
5. Skills & 1.98 & 11.76 & 4.95 & 23.53 & 13.86 & 41.18 & 32.67 & 11.76 & 46.53 & 11.76 \\
6. Clearness & 0.00 & 29.41 & 0.99 & 17.65 & 18.81 & 29.41 & 31.68 & 11.76 & 48.51 & 11.76 \\
7. Time & 0.00 & 23.53 & 3.96 & 23.53 & 15.84 & 29.41 & 35.64 & 11.76 & 44.55 & 11.76 \\
8. Enjoyment & 0.99 & 29.41 & 5.94 & 23.53 & 6.93 & 35.29 & 35.64 & 11.76 & 50.50 & 0.00 \\
9. Recommendation & 1.98 & 23.53 & 5.94 & 23.53 & 33.66 & 41.18 & 35.64 & 5.88 & 22.77 & 5.88 \\
\hline
\end{tabular}




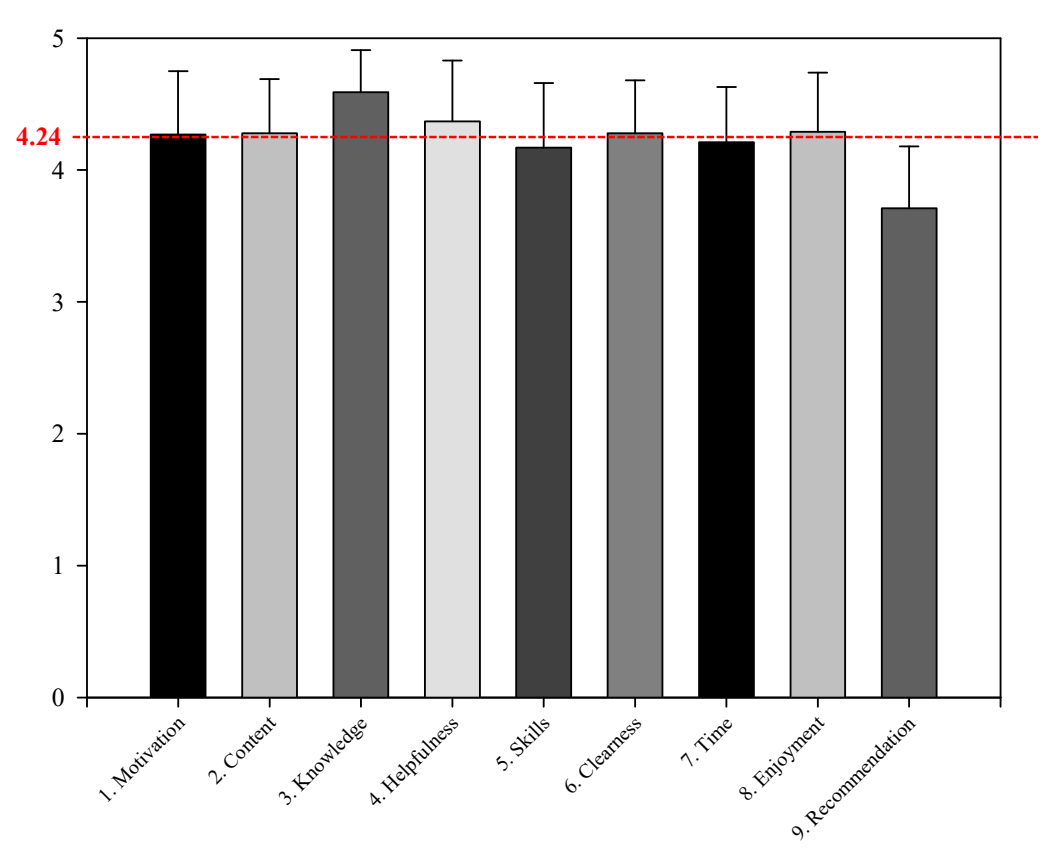

(a)

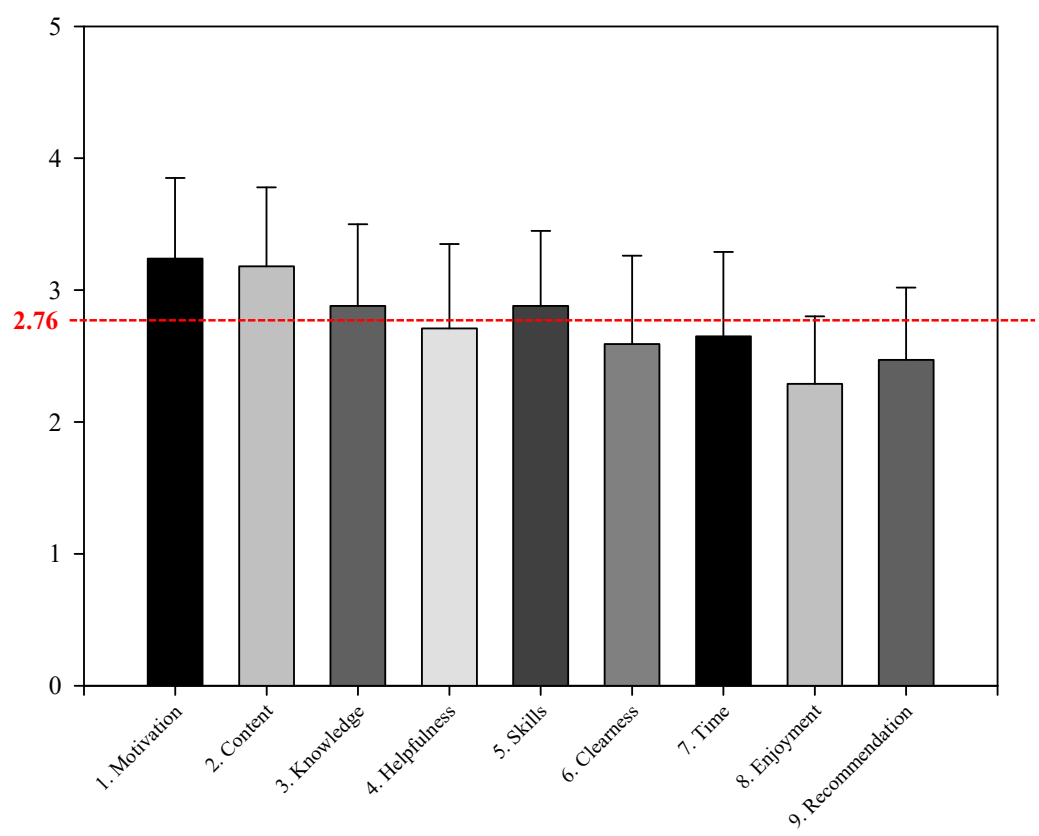

(b)

Figure 4. Obtained mean value from answers of students to questionnaire after performing (a) modeling-simulation and (b) traditional classes (red line represents the mean value of the questionnaire).

It is noted that the students' perspective after traditional classes was not clear in any direction and the mostly frequently obtained value was the 3 , on a scale of 1 (strongly disagree-absolutely no) to 5 (strongly agree-absolutely yes). The level motivation obtained was not very high, a $41.18 \%$ of students found them interesting (with 4 and 5 representing "interesting"), while a $35.29 \%$ of them give a value of 3 for the motivation item. Moreover, only $11.76 \%$ of students recommend using the 
traditional learning method in future editions of course for teaching fermentation-based biorefinery concepts (values of 4 or 5). Finally, lower value for items from 6-9 was notably observed in traditional lessons. Results for traditional classes showed that new and novelty teaching tools are required during higher education lessons, due to obtained results for traditional classes being significantly worse, with a mean value of 2.76 (more than 1 point less than for modeling-simulation ones, with a mean value of 4.30). Results of traditional classes reveal the low motivation of the students with teaching tools, where most of the questions were answered around the medium value (3).

Finally, Figure 5 shows the mean increase (\%) between results for modeling-simulation with respect to traditional classes. It is noted that students' perspective improved with the modeling-simulation classes, highlighting the enjoyment, because students thought that the modeling-simulation classes were more enjoyable than the traditional one (with an increase of $39.9 \%$ ).

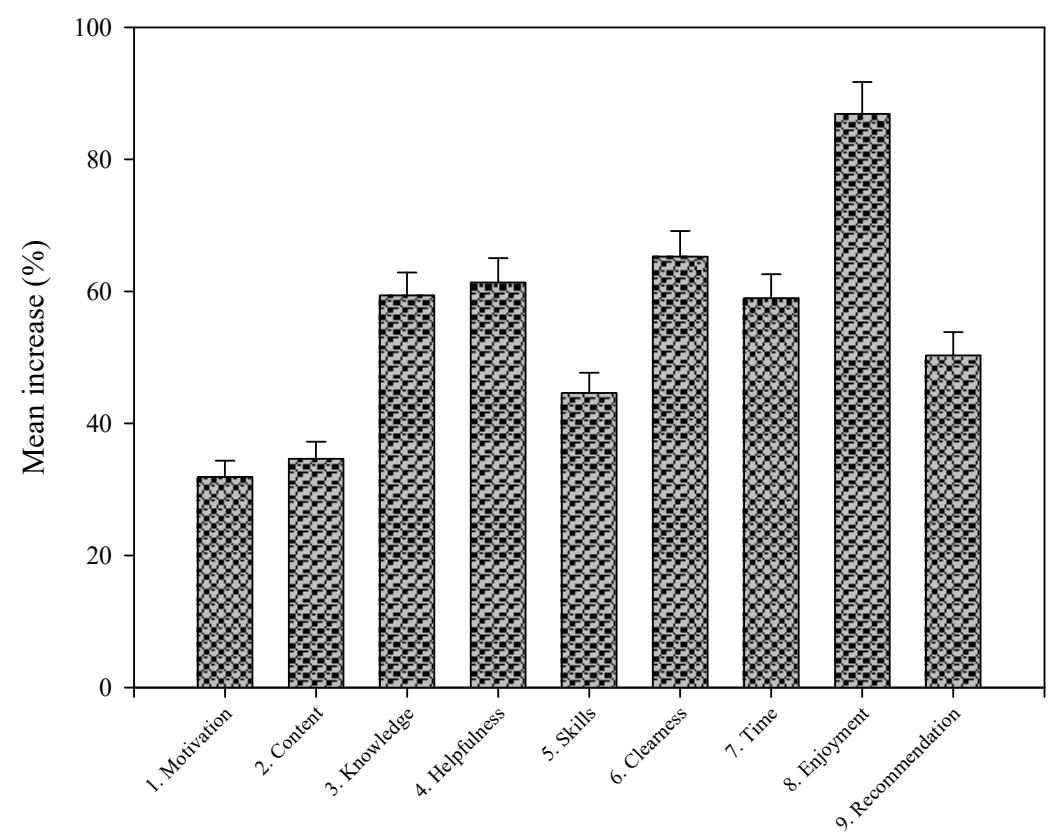

Figure 5. Mean increase (\%) between results for modeling-simulation classes with respect to traditional ones.

Figure 6 presents an assessment of how the activity significantly improved learning outcomes compared to the traditional teaching. In all questions, students that participated in modeling-simulation classes got a better score than students that received traditional classes based on the description of matter by the teacher and resolution of the same examples/exercises by the students but without the use of Berkeley Madonna software. Results showed that the differences between both teaching systems were especially substantial in questions one and four. These results were also observed by other authors $[8,11,18,30]$ in similar work experiences. Therefore, it can be concluded that the STEM students improved their skills when they were involved in an innovative learning based on modeling-simulation practices [12,31], achieving the proposed goals in the work. Findings indicate that changes embedding work-based learning into academic programs should be considered. 


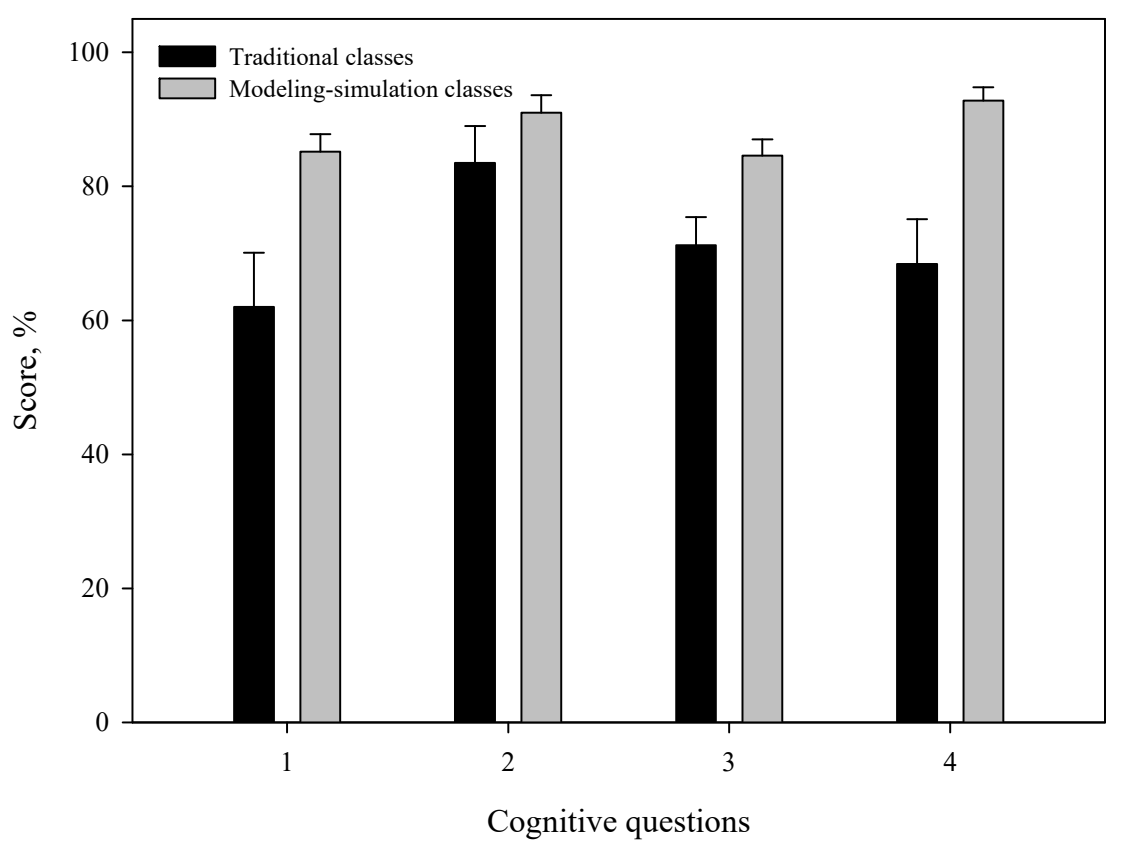

Figure 6. Mean score of students that perform the computer activities and students that do not perform these activities.

Table 5 shows the results of a multifactor analysis of variance for score, \%. The F-tests in the ANOVA table allowed to identify the significant factors. Since the three $P$-values are less than 0.05 , the factors cognitive question, methodology (traditional and modeling-simulation classes), and interactions of both factors have a statistically significant effect on Score, $\%$ at the $95.0 \%$ confidence level.

Table 5. Multifactor analysis of variance for score, $\%$.

\begin{tabular}{cccccc}
\hline Source & Sum of Squares & Df & Mean Square & F-Ratio & $p$-Value \\
\hline Main effects & & & & & \\
A: Cognitive question & 4346.69 & 3 & 1448.9 & 49.78 & 0.0000 \\
B: Methodology & $16,743.1$ & 1 & $16,743.1$ & 575.29 & 0.0000 \\
Interactions & & & & & \\
AB & 3217.23 & 3 & 1072.41 & 36.85 & 0.0000 \\
Residual & $13,504.1$ & 464 & 29.1036 & & \\
Total (corrected) & $35,968.5$ & 471 & & & \\
\hline
\end{tabular}

In addition, Table 6 applies a multiple comparison procedure to determine which means are significantly different from which others in function of cognitive question answered. In the table, the estimated differences between each pair of means are reported. An asterisk has been placed next to data when it shows a statistically significant difference at the $95.0 \%$ confidence level. Data showed all cognitive questions presented significant differences between traditional and modeling-simulation classes. 
Table 6. Multiple range tests for Score, \%, and methodology applied.

\begin{tabular}{lcc}
\hline & Difference & +/- Limits \\
\hline Cognitive question 1 & $24.4455^{*}$ & 3.33479 \\
Cognitive question 2 & $5.5795^{*}$ & 2.49947 \\
Cognitive question 3 & $15.1701^{*}$ & 3.05258 \\
Cognitive question 4 & $22.6476^{*}$ & 2.16768 \\
\hline
\end{tabular}

* An asterisk has been placed next to data when it shows a statistically significant difference at the $95.0 \%$ confidence level.

The authors also observed that the intrinsic capability of students, such as critical thinking ability and learning orientation, results in enhanced value of self-work-based dynamic modeling experience. In this sense, students learned how to use new technology and modeling tools that they will be able to use in their professional future, improving their overall abilities. These activities can be applied when the number of students is limited and the professor can follow their work. Moreover, students had to brainstorm jointly to solve the model, promoting team collaboration. Once the students got used to the software, they addressed real situations in biotechnology, in which the difficulty was increased with each practice. Finally, this activity created a high level of interest, enthusiasm, and engagement in the students (as it is shown in Table 3 and Figure 4a). Similar results were obtained by other authors who introduced active learning activities into their programs $[9,11,12,31-33]$. The obtained results suggest that designers in higher education can use the findings to adapt the current approach into a new teaching and learning methodology. Finally, in future courses, some specific software will be used to demonstrate techno-economic and environmental impact. Plant modeling simulated operating costs and the $\mathrm{CO}_{2}$ and $\mathrm{SO}_{2}$ emission will be determined to analyze if the overall bioethanol production from particular biomasses is or not economically favorable and environmentally benign. Previously, some researchers used HOMER and FermOpt software to perform this analysis [20,34]. In addition, commercially available process-simulation software packages (Aspen, SuperPro, etc.) will be applied to calculate cost data [17].

This study indicates that modeling-simulation practices can significantly increase both learning outcomes and motivation levels when they are compared with tradition teaching. Therefore, these techniques could be recommended an integral part of future biochemical engineering courses.

Regards implementation and adaptability, the methodology is quite flexible. The teacher can choose to spend more or less time on a concept, depending on the topics on which the teacher would like to focus, the student responses to leading questions, the teacher perceived student comprehension, and/or any questions students may pose. Additionally, this methodology could be converted into a self-guided handout given to students to work on at individual computers. This self-guided process would likely take longer than $30 \mathrm{~min}$ and would require the teacher to help individual students as they have questions.

The importance of engaging students in active learning experiences and the value of simulations make this demonstration a valuable addition to an upper-division biochemistry course. Modeling-simulation teaching emphasizes applications rather than memorization. However, unfortunately, modeling-simulations are used only sporadically in biochemical engineering courses. The promising results of this preliminary study merit additional data, including data from other courses, universities, and teachers. These future data will allow to deeply investigating links between modeling-simulation teaching methodology and impact on student satisfaction and learning outcomes. In addition, to fully install the modeling-simulations in biorefinery education in higher education, companies, researchers, and universities must work together to develop new software for the improvement education on biochemical engineering and/or bioprocesses.

To achieve the establishment of a new economic model, it is vital the improvement in the production and composition of raw materials and the development of processes of more efficient and 
inexpensive biomass conversion technologies, has built the most competitive bioproducts against their petrochemical counterparts.

The areas of knowledge in which special R\&D efforts must be made for the development of biorefinery are:

- Biomass production, from the point of view of improving performance and its characteristics as raw material for use in a biorefinery.

- Development of advanced biomass harvesting technologies based on biotechnology and thermochemical processes.

- Improvement of the performance of synthesis processes.

- Improvement of separation and purification operations of products, since they are to be obtained relatively diluted, it being essential to develop processes that allow concentrating and improving their purity.

Biotechnology and biochemical engineering play key roles in achieving these objectives. Thus, both disciplines could help in biomass production by improving crops both in terms of production (increasing their yields, its resistance to biotic and abiotic stress and decreasing its requirements, both nutrients, and care), and in terms of quality, generating crops that produce higher content of certain compounds, such as fats or sugary substrates, or lower content of substrates difficult to degrade or transform, such as lignin, which would reduce pretreatment operations. Another point in the chain where biotechnology and biochemical engineering has a prominent role is in biological transformation processes. The production of biocatalysts (microorganisms and enzymes) improved, more resistant and with greater activity and affinity for substrates, or actives in means that facilitate a subsequent separation of products of interest, will contribute greater efficiency and protection of the environment. In addition, optimization of bioreactor and separation operations plays a critical role in biorefineries to maximize product yields and improve overall process efficiency. In this sense, this work could contribute to better learning of modeling and simulation of bioreactors applied to the production of biofuels.

\section{Conclusions}

Dynamic modeling of batch, fed-batch, and continuous well-stirred bioreactors was used as a tool for teaching fermentation and optimization principles. The simulation classes were integrated into the traditional education program of "Biochemical Engineering Fundamentals" subject in order to improve the level of knowledge of the fermentation process and involved mechanisms during the bioethanol production. Students were taught to propose the necessary differential and algebraic equations to model the behavior of well-stirred tank bioreactors. Modeling-simulation training offered an added benefit to the traditional didactic instruction, enhancing the learning process. It was concluded that the students improved various capabilities in self-work-based experience. Finally, authors concluded that the use of new technologies and modeling tools will allow STEM students to improve their abilities in preparation for their professional future.

Author Contributions: Conceptualization, M.Á.M.-L.; methodology, M.Á.M.-L.; software, M.Á.M.-L. and A.R.; formal analysis, M.Á.M.-L. and A.R.; investigation, M.Á.M.-L.; writing—original draft preparation, M.Á.M.-L., and A.R.; writing-review and editing, M.Á.M.-L. and A.R. All authors have read and agreed to the published version of the manuscript.

Funding: This research received no external funding.

Acknowledgments: Authors would like to thank to Robert Macey and George Oster of University of California at Berkeley for developing Berkeley Madonna Software and students in Biotechnology of University of Granada for participating in the study.

Conflicts of Interest: The authors declare no conflict of interest. 


\section{References}

1. Darkwah, K.; Knutson, B.L.; Seay, J.R. A perspective on challenges and prospects for applying process systems engineering tools to fermentation-based biorefineries. ACS Sustain. Chem. Eng. 2018, 6, $2829-2844$. [CrossRef]

2. Hu, X.; Chang, S.; Li, J.; Qin, Y. Energy for sustainable road transportation in China: Challenges, initiatives and policy implications. Energy 2010, 35, 4289-4301. [CrossRef]

3. Henke, J.; Klepper, G.; Schmitz, N. Tax exemption for biofuels in Germany: Is bio-ethanol really an option for climate policy? Energy 2005, 30, 2617-2635. [CrossRef]

4. Malca, J.; Freire, F. Addressing land use change and uncertainty in the life-cycle assessment of wheat-based bioethanol. Energy 2012, 45, 519-527. [CrossRef]

5. Martín, M.d.1.M.B.; Rama, A.M.; Cruz, A.T.; Pérez, J.A.S. Using Berkeley Madonna for model development in Chemical Engineering education. @tic. Revista D'innovació Educativa 2014, 13, 41-48. [CrossRef]

6. Bruna, C. Motivating active learning of biochemistry through artistic representation of scientific concepts. J. Biol. Educ. 2013, 47, 46-51. [CrossRef]

7. Schwarz, S.; Westerheihden, D.F. Accreditation and Evaluation in the European Higher Education Area, 1st ed.; Springer: New York, NY, USA, 2007.

8. Rodríguez-Chueca, J.; Molina-García, A.; García-Aranda, C.; Pérez, J.; Rodríguez, E. Understanding sustainability and the circular economy through flipped classroom and challenge-based learning: An innovative experience in engineering education in Spain. Environ. Educ. Res. 2019, 26, $238-252$. [CrossRef]

9. Barlow, A.; Brown, S.; Lutz, B.; Pitterson, N.; Hunsu, N.; Adesope, O. Development of the student course cognitive engagement instrument (SCCEI) for college engineering courses. Int. J. STEM Educ. 2020, 7, 1-20. [CrossRef]

10. Venkatraman, S.; De Souza-Daw, T.; Kaspi, S. Improving employment outcomes of career and technical education students. High. Educ. Skills Work Based Learn. 2018, 8, 469-483. [CrossRef]

11. Campos, N.; Nogal, M.; Caliz, C.; Juan, A.A. Simulation-based education involving online and on-campus models in different European universities. Int. J. Educ. Technol. High. Educ. 2020, 17, 1-15. [CrossRef]

12. Çetin, M.; Demircan, H.Ö. Empowering technology and engineering for STEM education through programming robots: A systematic literature review. Early Child Dev. Care 2018, 190, 1323-1335. [CrossRef]

13. Erdmann, R.; Miller, K.; Stains, M. Exploring STEM postsecondary instructors' accounts of instructional planning and revisions. Int. J. STEM Educ. 2020, 7, 1-17. [CrossRef]

14. Baker, A.M.R.; Borin, S.; Chooi, K.P.; Huang, S.S.; Newgas, A.J.S.; Sodagar, D.; Ziegler, C.A.; Chan, G.H.T.; Walsh, K.A.P. Optimising microbial growth with a bench-top bioreactor. J. Biol. Educ. 2006, 41, 38-43. [CrossRef]

15. Ruiz, A.F.; Gil, M.C.T.; Corbo, A.C. Teaching microbial growth by simulation. J. Biol. Educ. 1989, $23,56-58$. [CrossRef]

16. Lutterschmidt, W.I.; Schaefer, J.F. A computer simulotion for demonstrating and modelling predatorprey oscillations. J. Biol. Educ. 1997, 31, 221-227. [CrossRef]

17. Ruiz-Ramos, E.; Romero-García, J.M.; Espínola, F.; Romero, I.; Hernández, V.; Castro, E. Learning and researching based on local experience and simulation software for graduate and undergraduate courses in chemical and environmental engineering. Educ. Chem. Eng. 2017, 21, 50-61. [CrossRef]

18. Bonde, M.T.; Makransky, G.; Wandall, J.; Larsen, M.V.; Morsing, M.; Jarmer, H.; Sommer, M.O.A. Improving biotech education through gamified laboratory simulations. Nat. Biotechnol. 2014, 32, 694-697. [CrossRef]

19. Potratz, J.P. Making enzyme kinetics dynamic via simulation software. J. Chem. Educ. 2018, 95, 482-486. [CrossRef]

20. Lay, M.; Swan, J. Evaluating FermOpt as a tool for teaching fermentation and optimization principles. In Proceedings of the International Conference on Engineering Education-ICEE, Coimbra, Portugal, 3-7 September 2007.

21. Ángel, S.-A. Real and virtual bioreactor laboratory sessions by STSE-CLIL WebQuest. Educ. Chem. Eng. 2015, 13, 1-8. [CrossRef]

22. Shanklin, T.; Roper, K.; Yegneswaaran, P.K.; Marten, M.R. Selection of bioprocess simulation software for industrial applications. Biotechnol. Bioeng. 2001, 72, 483-489. [CrossRef] 
23. Ospino, J.; Sánchez, M.; Secchi, A.R. Implementation of a block-oriented model library for undergraduate process control courses in EMSO simulator. Educ. Chem. Eng. 2017, 18, 45-57. [CrossRef]

24. Marcoline, F.; Grabe, M.; Nayak, S.; Zahnley, T.; Oster, G.; Macey, R. Berkeley Madonna User's Guide, July 2020. University of California. Berkeley Madonna, Inc. Available online: http://www.berkeleymadonna. com/downloads/BM_Users_Guide_10.1.pdf (accessed on 15 July 2020).

25. Dunn, I.J.; Heinzle, E.; Ingham, J.; Prenosil, J.E. Biological Reaction Engineering: Principles, Applications with PC Simulation, 2nd ed.; Wiley-VCH Verlag GmbH \& Co. KgaA: Weinheim, Germany, 2005.

26. Martín-Lara, M.A.; Ronda, A. Fundamentos de Ingeniería Bioquímica Prácticas Resueltas en Berkeley Madonna, 1st ed.; Universidad de Granada, Godel Impresiones S.L.: Granada, Spain, 2007.

27. Al-Moameri, H.H.; Jaf, L.A.; Suppes, G.J. Simulation Approach to Learning Polymer Science. J. Chem. Educ. 2018, 95, 1554-1561. [CrossRef]

28. Larrañeta, E. Incorporating stories of sedatives, spoiled sweet clover hay, and plants from the amazon rainforest into a pharmaceutical chemistry course to engage students and introduce drug design strategies. J. Chem. Educ. 2018, 95, 1778-1786. [CrossRef]

29. Zhu, B.; Feng, M.; Lowe, H.; Kesselman, J.; Harrison, L.; Dempski, R.E. Increasing enthusiasm and enhancing learning for biochemistry-laboratory safety with an augmented-reality program. J. Chem. Educ. 2018, 95, 1747-1754. [CrossRef]

30. Kamaliah, S.; Roslan, S.; Bakar, A.R.; Ghiami, Z. The effect of supervised work experience on the acquisition of employability skills among Malaysian students. High. Educ. Skills Work Based Learn. 2018, 8, 354-364. [CrossRef]

31. Garnett, J. Work-based learning. High. Educ. Skills Work Based Learn. 2016, 6, 305-314. [CrossRef]

32. Hinde, R.J.; Kovac, J. Student active learning methods in physical chemistry. J. Chem. Educ. 2001, 78, 93. [CrossRef]

33. Lu, X.; Anariba, F. Fostering innovation through an active learning activity inspired by the Baghdad battery. J. Chem. Educ. 2014, 91, 1929-1933. [CrossRef]

34. Hossain, N.; Razali, A.N.; Mahlia, T.M.I.; Chowdhury, T.; Chowdhury, H.; Ong, H.C.; Shamsuddin, A.H.; Silitonga, A.S. Experimental investigation, techno-economic analysis and environmental impact of bioethanol production from banana stem. Energies 2019, 12, 3947. [CrossRef]

Publisher's Note: MDPI stays neutral with regard to jurisdictional claims in published maps and institutional affiliations.

(C) 2020 by the authors. Licensee MDPI, Basel, Switzerland. This article is an open access article distributed under the terms and conditions of the Creative Commons Attribution (CC BY) license (http://creativecommons.org/licenses/by/4.0/). 